\title{
Screening of Prediabetes and Type 2 Diabetes Mellitus in Rabigh, Saudi Arabia
}

\author{
Amer Shafie Abdelrahman ${ }^{1}$, Zohair Jamil Gazzaz², Mohamad Nidal Khabaz, Marwan A. Bakarman ${ }^{3}$, AbdElaziz \\ Yaseen $^{4}$, Nadeem Shafique Butt ${ }^{3}$, Mohammad Alhabib ${ }^{5}$, Abdulrahman Majnuni ${ }^{5}$, Arif Abdulmohsen Almousa ${ }^{5}$, \\ Mohammad Alkayal ${ }^{5} \&$ Ahmad Azam Malik $^{3}$ \\ ${ }^{1}$ Department of Pathology, Rabigh Faculty of Medicine, King Abdulaziz University, Jeddah, Saudi Arabia \\ ${ }^{2}$ Department of Medicine, Rabigh Faculty of Medicine, King Abdulaziz University, Jeddah, Saudi Arabia \\ ${ }^{3}$ Department of Family and Community Medicine, Rabigh Faculty of Medicine, King Abdulaziz University, \\ Jeddah, Saudi Arabia \\ ${ }^{4}$ Consultant of Biostatistics, MOH, Saudi Arabia \& Prof. of Public health, Faculty of Medicine, Tanta University, \\ Egypt \\ ${ }^{5}$ Students of the sixth year at Rabigh Faculty of Medicine, King Abdulaziz University, Jeddah, Saudi Arabia \\ Correspondence: Dr. Amer Shafie Abdelrahman, Assistant Professor, MD, PhD, Department of Pathology, Rabigh \\ Faculty of Medicine, King Abdulaziz University, Jeddah, Saudi Arabia. Tel: 966-12-640-0000, Ext. 20078; Cell: \\ 966-508-945-432. E-mail: aaaali@kau.edu.sa
}

Received: January 11, 2018 Accepted: February 11, 2018 Online Published: February 19, 2018

doi:10.5539/gjhs.v10n3p161

URL: https://doi.org/10.5539/gjhs.v10n3p161

\begin{abstract}
Introduction: Identifying people with an increasing risk of diabetes provides a chance to change some factors before the occurrence of serious sequelae and permits the expectation of diabetes tendencies and the necessitated means to manage emerging diabetes. This current research aimed to screen students versus employees in Rabigh campus, King Abdulaziz University for the incidence of prediabetes and diabetes mellitus Type 2.
\end{abstract}

Methods: A sample of 279 was proportionally taken from student and employee study groups. Structured Modified Diabetic Risk Test (MDRT) questionnaire was adapted to be filled by each participant. Impaired glucose tolerance, body mass index, waist circumference and blood pressure of all participants were quantified. This study was done from January 2017 to March 2017.

Results: Higher pre-diabetic and diabetic risks were observed in employee as compared to students $\left(\mathrm{OR}_{\mathrm{Pre}-\mathrm{Dia}}=4.07\right.$ with $95 \% \mathrm{CI}=1.518-10.95 ; \mathrm{OR}_{\mathrm{Dia}}=2.913$ with $95 \%$ CI $\left.0.815-10.41\right)$. Waist circumference and body mass index of students showed significant association with glucose level with p values 0.003 and 0.002 respectively.

Conclusion: There are an alarming number of individuals with the risk of being affected by diabetes in both students and employees among this study population. These findings emphasize on the need for a primary healthcare clinic role in the screening, management, follow up and promoting community awareness of Diabetes Mellitus.

Keywords: Body Mass Index, diabetes, prediabetes, risk factors, waist circumference

\section{Introduction}

Diabetes and prediabetes are becoming more prevalent worldwide. Globally, during the past 20 years, the percentage of individuals with diabetes had increased more than twofold with rapid increase in type 2 diabetes (Zimmet, Magliano, Herman, \& Shaw, 2014). Diabetes is considered as one of the main health challenges of the $21^{\text {st }}$ century with life-changing complications among people living with this condition. It is expected that worldwide, nearly 5,100,000 deaths and more than eight percent of all death causes were regarded as being triggered by diabetes in 20-80-year-old patients. Around 415,000,000 persons are currently expected to develop diabetes with half of them unaware of it. In addition, there is 318,000,000 individuals show impaired glucose tolerance with an amplified diabetes development risk in the upcoming years, adding considerable burden to developing and less developed countries (IDF-Atlas, 2015). The International Diabetes Federation (IDF) 
considered Saudi Arabia among the countries with high diabetes prevalence of around $17.6 \%$. More than 30 million in the region are likely to experience impaired glucose tolerance and the number of diabetic patients will probably reach $72,100,000$ by 2040 . Diabetes was attributable to three hundred and forty-two thousand demises in the region in 2015. More than half of these deaths happened in patients under the age of 60 (IDF-Atlas, 2015). El Bcheraoui et al., reported that $14.8 \%$ of males and $11.7 \%$ of females were diabetic in 2013(El Bcheraoui et al., 2014). These figures increased with age, accounting for $7.8 \%$ among those aged $25-34$ and $50.4 \%$ among those aged 65 and older. Furthermore, prediabetes (borderline diabetes) was present in $15.2 \%$ of the Saudi population with similar age group. The disturbing rising tendency of diabetes incidence in a Saudi population of thirty million, constitutes a main medical and community health problem and a real challenge for health strategic planning (Alqurashi, Aljabri, \& Bokhari, 2011; Elhadd, Al-Amoudi, \& Alzahrani, 2007).

Quantifying the sum of population affected by diabetes, prediabetes and having the risk to develop diabetes is essential to permit balanced planning and distribution of funds and activation of prevention programs for this general health problem (Alqurashi et al., 2011). The risk factors related to type 2 diabetes (hereafter "diabetes") could be classified into two groups. First, modifiable risk factors that comprise overweight, abdominal obesity, fatty sugary diets, impaired glucose tolerance, elevated blood pressure $(\geq 140 / 90 \mathrm{mmHg})$, and decreased level of physical activity (Alberti, Zimmet, \& Shaw, 2007). In addition, there is accumulated evidence that indicates smoking as a risk factor (Yeh, Duncan, Schmidt, Wang, \& Brancati, 2010). The diabetes risk was observed higher, around $74 \%$ in females smoking $>40$ cigarettes daily, while this risk was around $45 \%$ in male smokers (Will, Galuska, Ford, Mokdad, \& Calle, 2001). Second, the non-modifiable risk factors are individuals who are more than 45 years of age, diabetes in first degree relatives, ethnicity, and history of diabetes in a preceding pregnancy (Alberti et al., 2007). Therefore, an idyllic risk evaluation or estimation model for diabetes should include both groups of risk factors (Bang et al., 2009).

The most serious complications associated with diabetes result from micro and/or macro-vascular pathology, and poor quality of health (Badran \& Laher, 2012). Therefore, great attention has been given to diabetes to prevent its critical consequences, starting from recognizing individuals at risk in earlier stages before diagnosis. This process has led to the term of prediabetes as an intermediary type of dysglycemia, i.e. prediabetes is a condition of high glucose level that has not yet reached a diabetic level. Individuals with impaired glucose tolerance $(140-200$ $\mathrm{mg} / \mathrm{dl}$ ), glycated hemoglobin (HbAlc) levels between 5.5-6.4\%, or fasting glucose (100-126 mg/dl) were defined as prediabetic who are at increased risk of developing diabetes and later its lethal complications (Association, 2014; Selvin et al., 2010). An individual may be prediabetic for years without knowing it. Prediabetes threatens a higher diabetes risk, cardiovascular disorders, especially in females and stroke mortality especially in the presence of obesity (IDF-Atlas, 2015; Levitzky et al., 2008; Seshasai, 2011). Prediabetic subjects are at an amplified diabetes risk as much as 3-10 times more than healthy individuals and up to $70 \%$ of them may develop type 2 diabetes during their lifetime (Control \& Prevention, 2013). Therefore, detection of prediabetes is crucial, considering the possibility of diabetes development. Recognizing prediabetic individuals increases the chance to control certain modifiable risk factors before the occurrence of significant consequences. Despite acknowledgment of increasing burden of Type 2 Diabetes Mellitus (DM), relevant data is limited from Saudi Arabia (Alotaibi, Perry, Gholizadeh, \& Al-Ganmi, 2017). This current research aimed to screen students and employees in Rabigh campus, King Abdulaziz University for the incidence of prediabetes and diabetes mellitus Type 2.

\section{Material and Methods}

In total, 279 subjects, from Rabigh campus of King Abdulaziz University, Saudi Arabia were involved in a preliminary screening program for prediabetes and diabetes. This study was done from January 2017 to March 2017. Announcement of the forthcoming research project was distributed by print posters and information sessions on campus. Interested participants were first screened in person to decide primary eligibility criteria. The early assessment assured that all participants were males, $\geq 18$ years of age, without previously detected diabetes and treatment affecting glucose level. All subjects who fulfilled the eligibility criteria and were interested in participating in the study were scheduled to join an in-person, onsite screening. A sample size of 279 was proportionally allocated to student and employee study groups to detect the difference of $4 \%$ in prevalence with $80 \%$ power of the test and $95 \%$ confidence level.

For this cross-sectional study, questionnaire was adapted and modified from well reputed validated diabetes risk tests (ADA, 2017; Makrilakis et al., 2011; Poltavskiy, Kim, \& Bang, 2016; Rydén et al., 2014; Yang, Hall, Piccolo, Maserejian, \& McKinlay, 2015). The first two added questions are modifications taken from the test designed by Professor Jaakko Tuomilehto and named Finnish Diabetes Risk Score (FINDRISC) (Tuomilehto et al., 2010). The possibility of developing diabetes was calculated depending on the total score of Modified Diabetic Risk Test 
(MDRT). Provisional scored survey, with 7 questions, was adapted from Poltavskiy \&Bang et al. (Bang et al., 2009; Poltavskiy et al., 2016). Some modifications were done including exclusion of gender, gestational diabetes and age-related questions since all participants were males and more than $95 \%$ of them were less than 40 years (score: 0 ). These questions were replaced by questions about waist circumference, types of meals, and smoking which are type 2 diabetes known risk factors. Six questions; 1, 2, 3, 5, 6 \& 7- of this MDRT were about behavioral modifiable risk factors; physical activity, meal type, blood pressure, smoking, BMI, and waist circumference respectively. Question number 4 was related to diabetic status of family members. The score of MDRT ranged from 0-10 and any participant who scored 5 or higher was presumed to have an elevated risk of diabetes according to Diabetes Risk Test adapted from Bang et al. (Bang et al., 2009; Poltavskiy et al., 2016) (see Appendix A).

All participants underwent measurement of waist circumference (WC), body mass index (BMI), as well as pressure of blood. We followed WHO criteria for those measurements (WHO, 2000, 2011; Zhou et al., 2017). Glucose-tolerance was tested using fast gluco-test (Bayer contour instrument with blood glucose test strips). Data was collected after acquiring written informed consent. King Abdulaziz University granted this study ethical approval in accordance with Helsinki declaration of 1975 and its latest amendments.

At the end of investigations, all individuals were persuaded to go on a self-monitored; diet, physical activity and weight control. Subjects who were at increased risk of being diabetic or prediabetic were advised to visit their family physician for confirmation, follow up and required treatment.

\subsection{Data Analysis}

The results were analyzed using IBM SPSS 21 version. Fisher's exact, Linear by Linear Association and chi-square tests has been applied to investigate the association of blood glucose levels with various risk factors and $\mathrm{p}$-values $<0.05$ considered significant. Multinomial logistic regression was applied to model the association between blood glucose values and Modified Diabetic Risk Test adjusted for group/s.

\section{Results}

The salient measurements of the study populations' general characteristics are presented in Table 1; the mean age, BMI and WC were 22.94 years, $26.18 \mathrm{Kg} / \mathrm{m}^{2}$, and $88.53 \mathrm{~cm}$ respectively. Table 2 shows blood glucose values classification and characteristics of studied population (students and employees); 209 (92.5\%) of students had normal blood glucose levels (without self-reported diabetes and not prediabetic), $10(4.4 \%)$ were prediabetic and 7 (3.1\%) were diabetic. Of the fifty-three employees, 41 (77.4\%), $8(15.1 \%)$, and $4(7.5 \%)$ were normal, prediabetic and diabetic. Higher pre-diabetic and diabetic risks were observed in employee as compared to students $\left(\mathrm{OR}_{\text {Pre-Dia }}=4.07\right.$ with $95 \% \mathrm{CI}=1.518-10.95 ; \mathrm{OR}_{\mathrm{Dia}}=2.913$ with $95 \%$ CI $\left.0.815-10.41\right)$. Overall $3.9 \%(\mathrm{n}-11)$ of the subjects were presumed to be diabetics as shown in Table 2. Body mass index measurements of students were as follow: $122(54 \%)$ were less than $25,41(18.1 \%)$ were between 25 and $<30$ and $63(27.9 \%)$ were $\geq 30$. Measurements of students' waist circumference showed that $151(66.8 \%)$ were $<94 \mathrm{~cm}, 48(21.2 \%)$ recorded more than 102 , and the rest were found to be in between the previous values. A clear majority $(92.5 \%)$ of the recruited students did not consume a healthy diet. $69.5 \%$ were physically inactive, $39.4 \%$ had a family history of diabetes, $38 \%$ were smokers and $14.1 \%$ had elevated blood pressure.

Recorded measurements of prediabetic students showed that over $80 \%$ had a BMI score $>25 ; 60 \%$ had WC $>94$; and $30 \%$ had diabetes family history. In addition, $70 \%$ were smokers, $80 \%$ reported low levels of exercise, and $100 \%$ had a diet rich in fat, salt, and sugar (Table 2). While the measured values of diabetic students revealed that $71 \%$ had a BMI score $\geq 30$, WC score $>102$ and had diabetic first-degree relatives with $85.7 \%$ reported low levels of exercise and consumed a daily fatty, salty, and sugary diet.

Table 1. General characteristics of the study groups

\begin{tabular}{lllll}
\hline Participant Groups & Number of Participants & Age (years) & BMI $\left(\mathbf{k g} / \mathbf{m}^{\mathbf{2}}\right)$ & Waist Circumference (cm) \\
\hline Students & 226 & $20.55 \pm 1.85$ & $26.37 \pm 6.95$ & $88.09 \pm 16.19$ \\
Employees & 53 & $33.15 \pm 10.45$ & $25.43 \pm 4.54$ & $90.39 \pm 11.71$ \\
Total & 279 & $22.94 \pm 6.9$ & $26.18 \pm 6.56$ & $88.53 \pm 15.45$ \\
\hline
\end{tabular}

Body mass index measurements of employees were as follow: 24 (45.3\%) were less than 25, $20(37.7 \%)$ were between 25 and $<30$ and $9(17 \%)$ were $\geq 30$. Measurements of their waist circumference showed that $32(60.4 \%)$ were $<94 \mathrm{~cm}, 7(13.2 \%)$ recorded more than 102, with the remaining measuring between the previous values. The 
majority (73.6\%) of the recruited employees group did not eat a healthy diet. $62.3 \%$ were physically inactive, $45.3 \%$ had a family history of diabetes, $35.8 \%$ were smokers and $17 \%$ had elevated blood pressure (Table 2 ).

Measurements of prediabetic employees showed that $37.5 \%$ had a BMI score $>25$; and only $12.5 \%$ measured WC score $>94$. More than $62.5 \%$ had a positive diabetes family history, and reported decreased physical activity, in addition to a rich fatty, salty and sugary diet (Table 2). The measured values of diabetic employees revealed that $75 \%$ had a BMI score $\geq 25,50 \%$ with a WC score $\geq 94,75 \%$ had diabetic first-degree relatives and $100 \%$ reported low levels of exercise and consumed a daily fatty, salty, and sugary diet.

Significant associations were seen in linear by linear association test among students with prediabetes and diabetes. BMI was significantly associated with glucose level with p-value equal to 0.003 . There are 7.358 more chances of developing prediabetes or diabetes status for those with high BMI/obese students (OR 7.358; 95\% CI: 1.386 39.057). Waist circumference is also significantly associated with blood glucose level in the students group with p-value equal to 0.002 ; there is 10.244 times more risk of developing prediabetes or diabetes status for the students with a waist circumference larger than $102 \mathrm{~cm}$ (OR 10.244; 95\% CI: $1.919-54.689$ ). Smoking, daily physical activity, diet and family history did not show statistically remarkable correlation with glucose level.

Table 2. Blood glucose levels by different characteristics of study sample

\begin{tabular}{|c|c|c|c|c|c|c|c|c|c|}
\hline & & \multicolumn{3}{|c|}{ Students Blood Glucose Level } & \multirow[b]{2}{*}{ P-value } & \multicolumn{3}{|c|}{ Employees Blood Glucose Level } & \multirow[b]{2}{*}{ P-value } \\
\hline & & $\begin{array}{l}\text { Normal } \\
(209)\end{array}$ & $\begin{array}{l}\text { Prediabetic } \\
\text { (10) }\end{array}$ & $\begin{array}{l}\text { Diabetic } \\
\text { (7) }\end{array}$ & & $\begin{array}{l}\text { Normal } \\
(41)\end{array}$ & $\begin{array}{l}\text { Prediabetic } \\
\text { (8) }\end{array}$ & $\begin{array}{l}\text { Diabetic } \\
\text { (4) }\end{array}$ & \\
\hline \multirow{3}{*}{ BMI } & $<25$ & 118 & 2 & 2 & \multirow{3}{*}{$\mathbf{0 . 0 0 3}^{\mathrm{a}}$} & 18 & 5 & 1 & \multirow{3}{*}{$0.885^{\mathrm{a}}$} \\
\hline & 25-29.9 & 38 & 3 & 0 & & 15 & 3 & 2 & \\
\hline & $\geq \mathbf{3 0}$ & 53 & 5 & 5 & & 8 & 0 & 1 & \\
\hline \multirow{3}{*}{ WC } & $<94 \mathrm{~cm}$ & 145 & 4 & 2 & \multirow{3}{*}{$0.002^{\mathrm{a}}$} & 23 & 7 & 2 & \multirow{3}{*}{$0.276^{\mathrm{a}}$} \\
\hline & $94-102 \mathrm{~cm}$ & 23 & 4 & 0 & & 11 & 1 & 2 & \\
\hline & $>102$ & 41 & 2 & 5 & & 7 & 0 & 0 & \\
\hline \multirow{2}{*}{$\begin{array}{l}\text { Elevated } \\
\text { BP }\end{array}$} & No & 179 & 9 & 6 & \multirow{2}{*}{$0.999^{\mathrm{b}}$} & 33 & 8 & 3 & \multirow{2}{*}{$0.409^{\mathrm{b}}$} \\
\hline & Yes & 30 & 1 & 1 & & 8 & 0 & 1 & \\
\hline \multirow{2}{*}{$\begin{array}{l}\text { Daily } \\
\text { Physical } \\
\text { Activity }\end{array}$} & Yes & 66 & 2 & 1 & \multirow[b]{2}{*}{$0.588^{\mathrm{b}}$} & 18 & 2 & 0 & \multirow[b]{2}{*}{$0.162^{b}$} \\
\hline & No & 143 & 8 & 6 & & 23 & 6 & 4 & \\
\hline \multirow{2}{*}{$\begin{array}{l}\text { Daily } \\
\text { Meal }\end{array}$} & $\begin{array}{l}\text { Vegetables } \\
\text { and fruits }\end{array}$ & 16 & 0 & 1 & \multirow[b]{2}{*}{$0.572^{\mathrm{b}}$} & 12 & 2 & 0 & \multirow[b]{2}{*}{$0.643^{b}$} \\
\hline & $\begin{array}{l}\text { Fatty, salty } \\
\text { and sugary }\end{array}$ & 193 & 10 & 6 & & 29 & 6 & 4 & \\
\hline \multirow{2}{*}{$\begin{array}{l}\text { Family } \\
\text { History }\end{array}$} & No & 137 & 128 & 7 & \multirow{2}{*}{$0.210^{\mathrm{b}}$} & 29 & 25 & 3 & \multirow{2}{*}{$0.252^{\mathrm{b}}$} \\
\hline & Yes & 89 & 81 & 3 & & 24 & 16 & 5 & \\
\hline \multirow{2}{*}{ Smoking } & No & 140 & 132 & 3 & \multirow{2}{*}{$0.104^{\mathrm{b}}$} & 34 & 24 & 6 & \multirow{2}{*}{$0.281^{\mathrm{b}}$} \\
\hline & Yes & 86 & 77 & 7 & & 19 & 17 & 2 & \\
\hline
\end{tabular}

BMI: body mass index; WC: waist circumference; BP: blood pressure; a Linear by Linear Association Test is applied; $b$ Fishers Exact Test is applied.

The diabetes risk was calculated depending on the total score of Modified Diabetic Risk Test (MDRT) of all participants. There were 212 participants with modified diabetic risk test score less than 5 , of which 15 were prediabetic and 4 were diabetic based on blood glucose level. On the other hand, 57 participants scored 5 or more, of which 3 were prediabetic and 7 were diabetic (Table 3). The measurements of blood glucose level and MDRT scores were significantly associated since the p-value is 0.008 .

Multinomial Logistic Regression was applied to test the significance of MDRT to classify blood glucose categories 
(Normal, Prediabetic and Diabetic). Table 4 summarizes the results of Multinomial Logistic Regression, $p$-value of MDRT is 0.005 in diabetic group, so the MDRT is a significant predictor to classify diabetic group. Also, the adjusted odds ratio for MDRT in diabetic group is 6.367 , i.e. there are 6.367 times more chances of being in diabetic group as compared to normal if MDRT score is $\geq 5$ adjusted for group (Students/Employees).

Table 3. Association of Blood Glucose with Modified Diabetic Risk Test Score

\begin{tabular}{|c|c|c|c|c|c|c|}
\hline & & \multicolumn{2}{|c|}{$\begin{array}{l}\text { Modified Diabetic Risk } \\
\text { Test Score }\end{array}$} & \multirow{2}{*}{$\begin{array}{l}\text { Odds Ratio } \\
\text { (95\% CI) }\end{array}$} & \multirow[t]{2}{*}{ Chi-Square } & \multirow[t]{2}{*}{ P-Value } \\
\hline & & $<5$ & $>=5$ & & & \\
\hline \multirow{3}{*}{$\begin{array}{l}\text { Blood Glucose } \\
\text { Level }\end{array}$} & Normal & 193 & 57 & & \multirow{3}{*}{10.198} & \multirow{3}{*}{0.008} \\
\hline & Prediabetic & 15 & 3 & $0.677(0.189-2.422)$ & & \\
\hline & Diabetic & 4 & 7 & $5.925(1.675-20.963)$ & & \\
\hline
\end{tabular}

Table 4. Multinomial Logistic Regression model to classify Blood Glucose level

\begin{tabular}{|c|c|c|c|c|c|c|c|c|}
\hline \multirow{2}{*}{\multicolumn{2}{|c|}{ Blood Glucose Level ${ }^{\text {a }}$}} & \multirow{2}{*}{$\boldsymbol{\beta}$} & \multirow{2}{*}{$\begin{array}{l}\text { Std. } \\
\text { Error }\end{array}$} & \multirow{2}{*}{ Wald } & \multirow{2}{*}{ P-Value } & \multirow{2}{*}{$\begin{array}{l}\text { Odds } \\
\text { Ratio }\end{array}$} & \multicolumn{2}{|c|}{ 95\% CI for Odds Ratio } \\
\hline & & & & & & & Lower Bound & Upper Bound \\
\hline \multirow[b]{2}{*}{ Prediabetic } & MDRT & -0.303 & 0.659 & 0.212 & 0.645 & $0.738^{\mathrm{b}}$ & 0.203 & 2.685 \\
\hline & $\begin{array}{l}\text { Group (Students/ } \\
\text { Employees) }\end{array}$ & 1.391 & 0.505 & 7.58 & 0.006 & 4.018 & 1.493 & 10.814 \\
\hline \multirow[b]{2}{*}{ Diabetic } & MDRT & 1.851 & 0.653 & 8.025 & 0.005 & $6.367^{\mathrm{b}}$ & 1.769 & 22.919 \\
\hline & $\begin{array}{l}\text { Group (Students/ } \\
\text { Employees) }\end{array}$ & 1.205 & 0.673 & 3.207 & 0.073 & 3.335 & 0.892 & 12.466 \\
\hline
\end{tabular}

${ }^{a}$ The reference category is: Normal, ${ }^{\mathrm{b}}$ Odds Ratio adjusted for Group.

\section{Discussion}

Proper usage of screening is a key factor in avoiding and controlling diabetes (Badran \& Laher, 2012). Several diabetic risk scores were used to recognize subjects with increased diabetes risk (ADA, 2017; Al-Lawati \& Tuomilehto, 2007; Bang et al., 2009; Makrilakis et al., 2011; Poltavskiy et al., 2016; Rydén et al., 2014; Yang et al., 2015). At present, risk score test for diabetes is internationally standardized and existing ones need to be tested among diverse groups in real-world settings (Bang et al., 2009). This study used questions from diabetic risk test of American Diabetes Association and Finnish Diabetes Risk Score with little modification ensuring its suitability for the participants of the present study (ADA, 2017; Bang et al., 2009; Makrilakis et al., 2011).

The outcomes of the current research revealed that $3.9 \%$ of the subjects are presumed to be undiagnosed diabetics and in need of further follow up and investigations for confirmation. This result is similar to El Bcheraoui et al. results and other relevant studies (Alqurashi et al., 2011; El Bcheraoui et al., 2014; Elhadd et al., 2007; IDF-Atlas, 2015). In addition, results revealed that $4.4 \%$ of students and $15.1 \%$ of employees were found to be suggestive of being prediabetic, which is also in harmony with the findings of Bcheraoui et al (2014) for similar age group of employees but not for students. Furthermore, the analysis of the study showed that commonly known diabetes behavioral risk factors (namely; blood pressure, smoking and family history) are poor predictors of prediabetes and diabetes, which presents contradiction with other studies (Grossman \& Messerli, 2008; Willi, Bodenmann, Ghali, Faris, \& Cornuz, 2007).

Higher BMI and large WC increased the probability of prediabetes or diabetes more than seven folds and ten folds respectively. These significant findings indicate that BMI and WC are key indicators of prediabetes as well as diabetes. The strength of waist circumference results is backed up by a study that tested the inter-relationships among demographic factors, physical activity and poor diet on prediabetes and concluded that a large WC had the greatest effect on prediabetes (Bardenheier et al., 2013). In addition, findings from the National Health and Nutrition Examination Survey (NHANES)2009-2010 has reported that the significance of sleep disorders on diabetes is attenuated when body mass index is included in the model, where the odds ratio for diabetes drops from 
$2.04(1.40,2.95)$ to $1.38(0.95,2.00)$. They conclude that the subject's obesity status plays a central role in the effect of sleep disorders on diabetes (Liu, Hay, \& Faught, 2013). Other studies have shown that BMI adjustment attenuates the association amongst the quality of diet and diabetes (Harding et al., 2004; Villegas et al., 2006), which supports our findings of BMI being a significant predictor of prediabetes and diabetes. The outcomes of the current study are in harmony with several other studies which have shown relation between diet and the risk of diabetes and prediabetes (Carter, Gray, Troughton, Khunti, \& Davies, 2010; Esposito \& Giugliano, 2011; McNaughton, Dunstan, Ball, Shaw, \& Crawford, 2009).However ,they also contradict a few other studies which have shown no association between diet quality, specifically total fat intake and red meat, and diabetic risk (Aune, Ursin, \& Veierød, 2009; Salmeron et al., 2001). The significant relation between increased BMI and WC with both prediabetes and diabetes may help guide future primary and secondary prevention programs where in addition to socioeconomic factors, BMI and large WC may need to be considered more important for better outcomes. Bardenheier and colleagues (Bardenheier et al., 2013) concluded that a large WC had the greatest effect on prediabetes, which is corresponding to our findings.

This study showed no association between few known diabetic risk factors and prediabetes. This may be explained by the fact that prediabetes is considered an early precursor state indicating likely eventual development of diabetes, and not the eventual established diabetes state itself in which the associated risk factors are more evident and strongly associated. Moreover, while the majority of prediabetic cases may end up being diagnosed with diabetes, not all cases will be; therefore, the expected relationship of known diabetes risk factors with prediabetes is diluted.

Besides BMI and WC, our study findings showed a considerable number of participants are at risk of being diabetic, according to Modified Diabetic Risk Test score based on the contributing factors including low level of physical activity, and bad eating habits. These results are in harmony with the outcomes of many studies which reported that obesity, sedentary lifestyle, physical inactivity and bad eating habits are the foremost reasons for diabetic prevalence increase in Saudi Arabia (Al-Lawati \& Tuomilehto, 2007; Al-Nozha et al., 2007; Al Hazzaa, 2004; Alqurashi et al., 2011).

Physical direct measures such as BMI and waist circumference may serve as a lifetime proxy for diet quality and level of physical activity compared to self-reported measures of health behaviors, taken at a single time point. While the reliability of self-reports of health conditions may be questioned, there is evidence that they are generally well correlated with medical record review (Okura, Urban, Mahoney, Jacobsen, \& Rodeheffer, 2004; Sauver et al., 2005).

Some limitations exist in this study. Fasting glucose was only measured once and may be subject to measurement error. The fact that measures are obtained at a single time point may reduce the likelihood of finding significant differences as research has shown that repeated measures of health behaviors may increase the significance and the effect size of such modifiable behaviors (Stringhini et al., 2010). The questionnaire was adapted and modified from two validated questionnaires, but this modified questionnaire used in this study needs to be tested and validated in further studies on larger population in similar or diverse settings. This study was planned in Rabigh campus, King Abdulaziz University, considering feasible conduction of study procedures including required measurements for screening and access to students representing local community (mostly Rabigh residents) as compared to conduction in community. The composition of the sample which covers only young to middle aged males is another limitation of the study. Countervailing strengths of this study include consideration of recognized behavioral risk factors, allowing assessment of their independent and joint influences on prediabetic and diabetic status. Additionally, further exploration among similar and other diverse community settings may also assist in better generalization of the findings.

\section{Conclusion}

In conclusion, the Modified Diabetic Risk Test of the present study can be a suitable tool for use as a preliminary tool in a screening program to predict the risk of developing prediabetes and diabetes but needs further exploration on larger population. Our results showed that BMI and WC were consistent predictors of prediabetes outcomes. The study findings have both clinical and public health impact: many different risk factors (including body mass index and waist circumference) are variably related to diabetes, prediabetes, and offer variably effective opportunities for primary and secondary prevention. By identifying the salient risk factors, future primary and secondary prevention initiatives can be more precisely targeted, resulting in more effective and cost-efficient outcomes. 


\section{Competing Interests Statement}

The authors declare that there are no conflicts of interest.

\section{References}

ADA, A. D. A. (2017). 2. Classification and diagnosis of diabetes. Diabetes care, 40(Supplement 1), S11-S24.

Al-Lawati, J., \& Tuomilehto, J. (2007). Diabetes risk score in Oman: a tool to identify prevalent type 2 diabetes among Arabs of the Middle East. Diabetes research and clinical practice, 77(3), 438-444.

Al-Nozha, M. M., Al-Hazzaa, H. M., Arafah, M. R., Al-Khadra, A., Al-Mazrou, Y. Y., Al-Maatouq, M. A., . . Abdullah, M. (2007). Prevalence of physical activity and inactivity among Saudis aged 30-70 years. Saudi Med J, 28(4), 559-568.

Al Hazzaa, H. (2004). Prevalence of physical inactivity in Saudi Arabia: A brief review.

Alberti, K. G. M. M., Zimmet, P., \& Shaw, J. (2007). International Diabetes Federation: a consensus on Type 2 diabetes prevention. Diabetic Medicine, 24(5), 451-463. https://doi.org/10.1111/j.1464-5491.2007.02157.x

Alotaibi, A., Perry, L., Gholizadeh, L., \& Al-Ganmi, A. (2017). Incidence and prevalence rates of diabetes mellitus in Saudi Arabia: An overview. Journal of Epidemiology and Global Health. https://doi.org/10.1016/j.jegh.2017.10.001

Alqurashi, K. A., Aljabri, K. S., \& Bokhari, S. A. (2011). Prevalence of diabetes mellitus in a Saudi community. Annals of Saudi medicine, 31(1), 19. https://doi.org/10.5144/0256-4947.2011.19

Association, A. D. (2014). Diagnosis and classification of diabetes mellitus. Diabetes care, 37(Supplement 1), S81-S90. https://doi.org/10.2337/dc14-S081

Aune, D., Ursin, G., \& Veierød, M. (2009). Meat consumption and the risk of type 2 diabetes: a systematic review and meta-analysis of cohort studies. Springer.

Badran, M., \& Laher, I. (2012). Type II diabetes mellitus in Arabic-speaking countries. International journal of endocrinology, 2012. https://doi.org/10.1155/2012/902873

Bang, H., Edwards, A. M., Bomback, A. S., Ballantyne, C. M., Brillon, D., Callahan, M. A., . . Kern, L. M. (2009). Development and validation of a patient self-assessment score for diabetes risk. Annals of internal medicine, 151(11), 775-783. https://doi.org/10.7326/0003-4819-151-11-200912010-00005

Bardenheier, B. H., Bullard, K. M., Caspersen, C. J., Cheng, Y. J., Gregg, E. W., \& Geiss, L. S. (2013). A novel use of structural equation models to examine factors associated with prediabetes among adults aged 50 years and older. Diabetes care, 36(9), 2655-2662. https://doi.org/10.2337/dc12-2608

Carter, P., Gray, L. J., Troughton, J., Khunti, K., \& Davies, M. J. (2010). Fruit and vegetable intake and incidence of type 2 diabetes mellitus: systematic review and meta-analysis. Bmj, 341, c4229. https://doi.org/10.1136/bmj.c4229

Control, C. f. D., \& Prevention. (2013). Awareness of prediabetes--United States, 2005-2010. MMWR. Morbidity and mortality weekly report, 62(11), 209.

El Bcheraoui, C., Basulaiman, M., Tuffaha, M., Daoud, F., Robinson, M., Jaber, S., . . AlMazroa, M. A. (2014). Status of the diabetes epidemic in the Kingdom of Saudi Arabia, 2013. International journal of public health, 59(6), 1011-1021. https://doi.org/10.1007/s00038-014-0612-4

Elhadd, T. A., Al-Amoudi, A. A., \& Alzahrani, A. S. (2007). Epidemiology, clinical and complications profile of diabetes in Saudi Arabia: A review. Annals of Saudi medicine, 27(4), 241. https://doi.org/10.4103/0256-4947.51484

Esposito, K., \& Giugliano, D. (2011). Increased consumption of green leafy vegetables, but not fruit, vegetables or fruit and vegetables combined, is associated with reduced incidence of type 2 diabetes. Evidence-based medicine, 16(1), 27-28. https://doi.org/10.1136/ebm1152

Grossman, E., \& Messerli, F. H. (2008). Hypertension and diabetes Cardiovascular diabetology: Clinical, metabolic and inflammatory facets (Vol. 45, pp. 82-106). Karger Publishers. https://doi.org/10.1159/000115189

Harding, A.-H., Day, N. E., Khaw, K.-T., Bingham, S., Luben, R., Welsh, A., \& Wareham, N. J. (2004). Dietary fat and the risk of clinical type 2 diabetes: the European prospective investigation of Cancer-Norfolk study. American journal of epidemiology, 159(1), 73-82. https://doi.org/10.1093/aje/kwh004 
IDF-Atlas, D. (2015). International Diabetes Federation, Brussels, 2015.

Levitzky, Y. S., Pencina, M. J., D'Agostino, R. B., Meigs, J. B., Murabito, J. M., Vasan, R. S., \& Fox, C. S. (2008). Impact of impaired fasting glucose on cardiovascular disease: the Framingham Heart Study. Journal of the American College of Cardiology, 51(3), 264-270. https://doi.org/10.1016/j.jacc.2007.09.038

Liu, J., Hay, J., \& Faught, B. E. (2013). The association of sleep disorder, obesity status, and diabetes mellitus among US adults-The NHANES 2009-2010 survey results. International journal of endocrinology, 2013. https://doi.org/10.1155/2013/234129

Makrilakis, K., Liatis, S., Grammatikou, S., Perrea, D., Stathi, C., Tsiligros, P., \& Katsilambros, N. (2011). Validation of the Finnish diabetes risk score (FINDRISC) questionnaire for screening for undiagnosed type 2 diabetes, dysglycaemia and the metabolic syndrome in Greece. Diabetes \& metabolism, 37(2), 144-151. https://doi.org/10.1016/j.diabet.2010.09.006

McNaughton, S. A., Dunstan, D. W., Ball, K., Shaw, J., \& Crawford, D. (2009). Dietary quality is associated with diabetes and cardio-metabolic risk factors. The Journal of nutrition, 139(4), 734-742. https://doi.org/10.3945/jn.108.096784

Okura, Y., Urban, L. H., Mahoney, D. W., Jacobsen, S. J., \& Rodeheffer, R. J. (2004). Agreement between self-report questionnaires and medical record data was substantial for diabetes, hypertension, myocardial infarction and stroke but not for heart failure. Journal of clinical epidemiology, 57(10), 1096-1103. https://doi.org/10.1016/j.jclinepi.2004.04.005

Poltavskiy, E., Kim, D. J., \& Bang, H. (2016). Comparison of screening scores for diabetes and prediabetes. Diabetes research and clinical practice, 118, 146-153.

Rydén, L., Grant, P. J., Anker, S. D., Berne, C., Cosentino, F., Danchin, N., ... Huikuri, H. (2014). ESC guidelines on diabetes, pre-diabetes, and cardiovascular diseases developed in collaboration with the EASD-summary. Diabetes \& vascular disease research, 11(3), 133-173.

Salmeron, J., Hu, F. B., Manson, J. E., Stampfer, M. J., Colditz, G. A., Rimm, E. B., \& Willett, W. C. (2001). Dietary fat intake and risk of type 2 diabetes in women. The American journal of clinical nutrition, 73(6), 1019-1026.

Sauver, J. L. S., Hagen, P. T., Cha, S. S., Bagniewski, S. M., Mandrekar, J. N., Curoe, A. M., . . Jacobsen, S. J. (2005). Agreement between patient reports of cardiovascular disease and patient medical records. Paper presented at the Mayo Clinic Proceedings. https://doi.org/10.4065/80.2.203

Selvin, E., Steffes, M. W., Zhu, H., Matsushita, K., Wagenknecht, L., Pankow, J., . . Brancati, F. L. (2010). Glycated hemoglobin, diabetes, and cardiovascular risk in nondiabetic adults. $N$ Engl J Med, 2010(362), 800-811. https://doi.org/10.1056/NEJMoa0908359

Seshasai, S. (2011). Diabetes Mellitus, Fasting Glucose, and Risk of Cause-Specific Death (vol 364, pg 829, 2011). New England Journal of Medicine, 364(13), 1281-1281. https://doi.org/10.1056/NEJMx110023

Stringhini, S., Sabia, S., Shipley, M., Brunner, E., Nabi, H., Kivimaki, M., \& Singh-Manoux, A. (2010). Association of socioeconomic position with health behaviors and mortality. Jama, 303(12), 1159-1166. https://doi.org/10.1001/jama.2010.297

Tuomilehto, J., Lindström, J., Hellmich, M., Lehmacher, W., Westermeier, T., Evers, T., . . Chiasson, J.-L. (2010). Development and validation of a risk-score model for subjects with impaired glucose tolerance for the assessment of the risk of type 2 diabetes mellitus-The STOP-NIDDM risk-score. Diabetes research and clinical practice, 87(2), 267-274.

Villegas, R., Shu, X. O., Gao, Y.-T., Yang, G., Cai, H., Li, H., \& Zheng, W. (2006). The association of meat intake and the risk of type 2 diabetes may be modified by body weight. International journal of medical sciences, 3(4), 152. https://doi.org/10.7150/ijms.3.152

WHO. (2000). Obesity: preventing and managing the global epidemic. World Health Organization.

WHO. (2011). Waist circumference and waist-hip ratio: report of a World Health Organization. Expert Consultation.

Will, J. C., Galuska, D. A., Ford, E. S., Mokdad, A., \& Calle, E. E. (2001). Cigarette smoking and diabetes mellitus: evidence of a positive association from a large prospective cohort study. International journal of epidemiology, 30(3), 540-546. https://doi.org/10.1093/ije/30.3.540 
Willi, C., Bodenmann, P., Ghali, W. A., Faris, P. D., \& Cornuz, J. (2007). Active smoking and the risk of type 2 diabetes: a systematic review and meta-analysis. Jama, 298(22), 2654-2664. https://doi.org/10.1001/jama.298.22.2654

Yang, M. H., Hall, S. A., Piccolo, R. S., Maserejian, N. N., \& McKinlay, J. B. (2015). Do behavioral risk factors for prediabetes and insulin resistance differ across the socioeconomic gradient? Results from a community-based epidemiologic survey. International journal of endocrinology, 2015. https://doi.org/10.1155/2015/806257

Yeh, H.-C., Duncan, B. B., Schmidt, M. I., Wang, N.-Y., \& Brancati, F. L. (2010). Smoking, Smoking Cessation, and Risk for Type 2 Diabetes MellitusA Cohort Study. Annals of internal medicine, 152(1), 10-17. https://doi.org/10.7326/0003-4819-152-1-201001050-00005

Zhou, B., Bentham, J., Di Cesare, M., Bixby, H., Danaei, G., Cowan, M. J., . . . Zu-iga Cisneros, J. (2017). Worldwide trends in blood pressure from 1975 to 2015: a pooled analysis of 1479 population-based measurement studies with 19\&\#xb7;1 million participants. The Lancet, 389(10064), 37-55. https://doi.org/10.1016/S0140-6736(16)31919-5

Zimmet, P. Z., Magliano, D. J., Herman, W. H., \& Shaw, J. E. (2014). Diabetes: a 21 st century challenge. The lancet Diabetes \& endocrinology, 2(1), 56-64. https://doi.org/10.1016/S2213-8587(13)70112-8 
Appendix A

Screening of prediabetes and Type 2 Diabetes Mellitus in Rabigh, Saudi Arabia

- Weight

Height

Body mass index

- Waste circumference

- Blood pressure

- Glucose in blood:

Fasting

Random

Modified Diabetic Risk Test (MDRT)

1. Do you usually have daily at least $30 \mathrm{M}$ physical activity?

a) Yes (0 point)

b) No (1 point)

2. What is your main meal?

a) Daily vegetables and fruits ( 0 point)

b) Daily fatty, salty, sugary food (1 point)

3. Have you ever been diagnosed with high blood pressure?

a) Yes (1 point)

b) No (0 point)

4. Do you have mother, father, sister or brother with diabetes?

a) Yes (1 point)

b) No (0 point)

5. Do you smoke nowadays?

a) Yes (1 point)

b) No (0 points)

6. Body mass index?

a) Lower than $25 \mathrm{Kg} / \mathrm{m} 2$ (0 points)

b) $25-30 \mathrm{Kg} / \mathrm{m} 2$ (1 points)

c) Higher than $30 \mathrm{Kg} / \mathrm{m} 2$ (2 points)

d) Higher than $40 \mathrm{Kg} / \mathrm{m} 2$ (3 points)

7. Waist circumference below the ribs?

a) Less than $94 \mathrm{~cm}$ (0 points)

b) $94-102 \mathrm{~cm}$ (1 points)

c) More than 102 (2 points)

Write your score
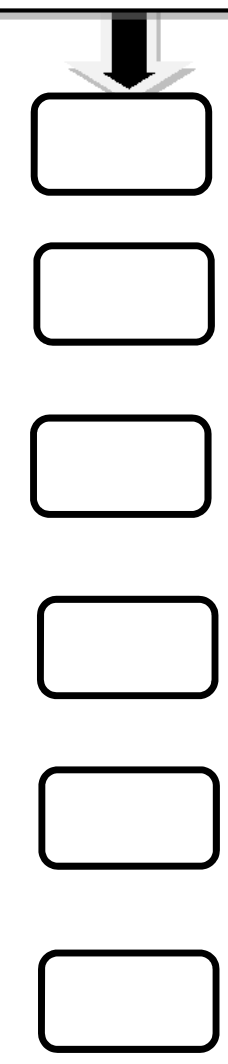

Total Score: 
If you scored 5 or higher:

You are at increased risk for having type 2 diabetes. However, only your doctor can tell for sure if you do have type 2 diabetes or prediabetes (a condition that precedes type 2 diabetes in which blood glucose levels are higher than normal). Talk to your doctor to see if additional testing is needed.

\section{Copyrights}

Copyright for this article is retained by the author(s), with first publication rights granted to the journal.

This is an open-access article distributed under the terms and conditions of the Creative Commons Attribution license (http://creativecommons.org/licenses/by/4.0/). 